\title{
Anti-grazing properties of the toxic dinoflagellate Karlodinium veneficum during predator-prey interactions with the copepod Acartia tonsa
}

\author{
Rebecca J. Waggett ${ }^{1, *}$, Patricia A. Tester ${ }^{1}$, Allen R. Place ${ }^{2}$ \\ ${ }^{1}$ National Ocean Service, National Oceanic and Atmospheric Administration, 101 Pivers Island Road, Beaufort, \\ North Carolina 28516-9722, USA
}

${ }^{2}$ University of Maryland Biotechnology Institute, Center of Marine Biotechnology, Suite 236, 701 East Pratt Street, Baltimore, Maryland 21202, USA

\begin{abstract}
Karlodinium veneficum (syn. Karlodinium micrum, Bergholtz et al. 2006; J Phycol 42: 170-193) is a small athecate dinoflagellate commonly present in low levels in temperate, coastal waters. Occasionally, $K$. veneficum forms ichthyotoxic blooms due to the presence of cytotoxic, hemolytic compounds, putatively named karlotoxins. To evaluate the anti-grazing properties of these karlotoxins, we conducted food removal experiments using the cosmopolitan copepod grazer Acartia tonsa. Wild-caught, adult female $A$. tonsa were exposed to 6 monoalgal or mixed algal diets made using bloom concentrations of toxic (CCMP 2064) and non-toxic (CSIC1) strains of $K$. veneficum. Ingestion and clearance rates were calculated using the equations of Frost (1972). Exposure to the toxic strain of $K$. veneficum did not contribute to an increased mortality of the copepods and no significant differences in copepod mortality were found among the experimental diets. However, A. tonsa had significantly greater clearance and ingestion rates when exposed to a monoalgal diet of the non-toxic strain CSIC1 than when exposed to the monoalgal diet of toxic strain CCMP 2064 and mixed diets dominated by this toxic strain. These results support the hypothesis that karlotoxins in certain strains of $K$. veneficum deter grazing by potential predators and contribute to the formation and continuation of blooms.
\end{abstract}

KEY WORDS: Copepod grazing - Harmful algae - Toxic dinoflagellate $\cdot$ Chemical deterrent Karlodinium $\cdot$ Karlotoxin

\section{INTRODUCTION}

A complex interaction of physical and biological factors regulates the formation and maintenance of harmful algal blooms (HABs). Zooplankton, particularly copepods, are major grazers of oceanic phytoplankton and are capable of influencing and regulating phytoplankton dynamics (Stoecker \& Sanders 1985, Watras et al. 1985, Granéli et al. 1993). However, many HAB-forming species have evolved anti-grazing strategies that may contribute to and enhance bloom formation. Anti-grazing strategies may involve morphological adaptations, including spines or large size (Nielsen 1991), chemical deterrents such as toxins or metabolites (Huntley et al. 1986, Ives 1987, Teegarden
1999), or the production of external mucous exudates (Liu \& Buskey 2000). Species composition of available grazers at the time of a HAB event may also influence bloom success due to their individual prey preferences, selective predation, and grazing potential (Teegarden \& Cembella 1996). Previous reports indicate that certain HAB species deter grazing through the production of toxins (Huntley et al. 1986, Ives 1987, Uye \& Takamatsu 1990, Teegarden 1999, Wolfe 2000) and recent evidence suggests that Karlodinium veneficum falls within this category (Vaqué et al. 2006, Adolf et al. 2007, Adolf et al. in press).

Karlodinium veneficum (Ballantine, 1956) Larsen, 2000 (syn. K. micrum [Leadbeater \& Dodge, 1966] Larsen, 2000) is a small (ca. 8 to $12 \mu \mathrm{m}$ diameter) athe- 
cate dinoflagellate common in temperate coastal waters. Investigations by Bergholtz et al. (2006) confirmed that $K$. micrum and $K$. veneficum are morphologically indistinguishable and sparse genetic differences indicate they are conspecifics (Bergholtz et al. 2006). Additionally, Garcés et al. (2006) have confirmed that Gyrodinium corsicum Paulmier, Berland, Billard \& Nezan, 1995, commonly found in European waters, is also a member of the genus Karlodinium, specifically the species $K$. veneficum and $K$. armiger Bergholtz, Daugbjerg et Moestrup, 2006. Of particular relevance, $K$. veneficum is present in estuaries, brackish ponds and aquaculture systems in the southeastern USA (Deeds et al. 2002, Kempton et al. 2002, Deeds et al. 2004, Fensin 2004, Hall et al. 2008). It is routinely

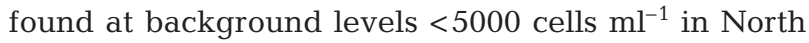
Carolina estuaries, but occasionally reaches abundances $>30000$ cells ml-1 (Fensin 2004). Bloom levels of $K$. veneficum, $>10^{4}$ cells $\mathrm{ml}^{-1}$, have been associated with fish kills in coastal waters of the southeastern USA (Deeds et al. 2002, Kempton et al. 2002, Deeds et al. 2004, Fensin 2004, Hall et al. 2008).

Hemolytic, cytotoxic and ichthyotoxic toxins from Karlodinium veneficum have been identified as polar lipid-like compounds putatively called karlotoxins (Deeds et al. 2002, 2006). Two karlotoxin variations have been identified; the variant from $K$. veneficum strains found in Chesapeake Bay waters is referred to as KmTx 1, while the variant from strains found in estuaries in the southeastern USA is referred to as KmTx 2 (Deeds et al. 2004). Both KmTx 1 and 2 are acutely toxic to fish. Toxins affect gills by increasing membrane permeability resulting in cell death through osmotic cell lysis (Deeds et al. 2006). Toxin content varies among strains of $K$. veneficum, with highest values found in strain CCMP 2064 and being apparently absent in strain MD5 isolated from the Choptank River, Maryland, and maintained at Horn Point Laboratory (Adolf et al. 2007). Toxic effects have been reported for strain CSIC1 isolated from the Alfacs Bay (Ebro Delta, Mediterranean Sea, Spain) and maintained at the Institut de Cienciès del Mar, Barcelona, Spain (Vaqué et al. 2006); however, no toxins have been identified via liquid chromatography-mass spectroscopy (LC-MS).

It has been suggested that karlotoxin may also serve as an anti-grazing compound. Lethal effects of Karlodinium veneficum vary given the toxicity of the strain and the sensitivity of the exposed grazer. Paralysis and mortality of the copepod Acartia grani has been reported within hours of incubation when exposed to K. veneficum (previously Gyrodinium corsicum Paulmier) isolated from a natural bloom event (Delgado \& Alcaraz 1999) and after prolonged exposure (288 h) to the cultured $K$. veneficum (da Costa et al. 2005). However, Vaqué et al. (2006) revealed no lethal effects on the copepod A. margalefi following $24 \mathrm{~h}$ incubation with $K$. veneficum strain CSIC1, although egg viability was significantly reduced. Additionally, no lethal effects were observed for the harpacticoid copepod Euterpina acutifrons after $>288 \mathrm{~h}$ exposure to strain CSIC1 (da Costa et al. 2005). Previous research also suggests that ingestion rates of micro- and mesozooplankton predators may be affected by karlotoxin presence. Adolf et al. (2007) found when comparing the dinoflagellate predator Oxyrrhis marina's feeding rate on the toxic $K$. veneficum strain CCMP 2064 to its feeding rate on the non-toxic MD5 strain that exposure to the toxic strain significantly reduced grazing. Additionally, both the presence of CCMP 2064 and of purified karlotoxin inhibited grazing in mixed-prey cultures (Adolf et al. 2007). Since the free toxin content in non-grazed culture was $<5 \%$ of the total karlotoxin content, it was suggested that prey may release toxin as a result of grazing activity.

The calanoid copepod Acartia tonsa Dana, 1849 is routinely exposed to background levels of Karlodinium veneficum in coastal waters of the southeastern USA, and populations are expected to be present during bloom formation. In the present study, we quantified mortality and grazing efficiency of $A$. tonsa on 6 monoalgal and mixed diets of toxic and non-toxic $K$. veneficum strains to evaluate the anti-grazing properties of karlotoxins.

\section{MATERIALS AND METHODS}

Experimental organisms. Karlodinium veneficum strains CCMP 2064 from Provasoli-Guillard National Center for Culture of Marine Phytoplankton and CSIC1 from Institut de Cienciès del Mar, Barcelona, Spain were cultured in K media (Keller et al. 1987) at a salinity of $20 \mathrm{ppt}$. They were maintained at $22^{\circ} \mathrm{C}$ on a $12 \mathrm{~h}$ light-dark cycle with $94.5 \pm 12.0 \mu \mathrm{mol}$ quanta $\mathrm{m}^{-2}$ $\mathrm{s}^{-1}$ photosynthetically active radiation (PAR). The CCMP 2064 strain (TOX) was identified as toxic and strain CSIC1 (NONTOX) as non-toxic (A. R. Place \& J. E. Adolf pers. comm.). Cell densities and average cell diameters were monitored daily using a Beckman Multisizer 3 Coulter Counter interfaced with a PC running Multisizer 3 v. 3.51 software. Experiments were run with cultures in the exponential phase of their growth cycle.

Plankton tows were conducted from the NOAA dock on Pivers Island, Beaufort, North Carolina $\left(34^{\circ} 41.8^{\prime} \mathrm{N}\right.$ $76^{\circ} 40.2^{\prime} \mathrm{W}$ ), by suspending a $102 \mu \mathrm{m}$ mesh, $0.5 \mathrm{~m}$ diameter plankton net in the outgoing tide for up to $45 \mathrm{~min}$. Contents of the cod end were diluted with ambient seawater and returned to the laboratory. The plankton tow was gently poured through a $300 \mu \mathrm{m}$ 
mesh sieve and the retained zooplankton were roughly sorted to remove any large predators (chaetognaths and ctenophores). The zooplankton were added to $4 \mathrm{l}$, $0.22 \mu \mathrm{m}$ filtered seawater at a salinity of $30 \mathrm{ppt}$, aerated, fed a mixture of Rhodomonas sp. (Cryptophyceae) and Isochrysis galbana (Prymnesiophyceae) daily, and acclimated at room temperature (ca. 20 to $24^{\circ} \mathrm{C}$ ) under an ambient light-dark cycle. Salinity was reduced to $20 \mathrm{ppt}$ over a $2 \mathrm{~d}$ period by diluting $5 \mathrm{ppt} \mathrm{d}^{-1}$ with deionized water. Zooplankton were given an additional $24 \mathrm{~h}$ to acclimate to this salinity before experimentation. On the day of experimentation, adult females of the copepod species Acartia tonsa were isolated from the plankton under a dissecting microscope. Individuals were examined to ensure antennules were intact and they appeared healthy and free of external parasites. Twenty female $A$. tonsa were held within each of 21 individual $25 \mathrm{ml}$ plastic cups filled with $10 \mathrm{ml}$ sterile-filtered seawater (20 ppt).

Biochemical analyses. Three subsamples of each Karlodinium veneficum strain were filtered through pre-combusted Pall Type A/E $13 \mathrm{~mm}$ filters and frozen for particulate $\mathrm{C}$ and $\mathrm{N}$ analysis. Prior to analysis, filters were fumed overnight with concentrated $\mathrm{HCl}$ to remove excess inorganic carbon. Filters were then dried for $1 \mathrm{~h}$ at $100^{\circ} \mathrm{C}$ and analyzed on a Costech Elemental Combustion System (ECS) 4010 interfaced with a PC running Elemental Analysis Software (EAS). Samples $(4 \mathrm{ml})$ of the cultures were filtered through $13 \mathrm{~mm}$ PTFE syringe filters (Whatman, $0.2 \mu \mathrm{m}$ pore size) and sent for analysis at the University of Maryland Biotechnology Institute Center of Marine Biotechnology. Karlotoxin analysis was performed using LCMS following the methods of Bachvaroff et al. (2008).

Karlodinium veneficum grazing experiments. We conducted 3 complete suites of food removal experiments (Experiments 1,2 and 3) using adult Acartia tonsa females fed 6 diets of monocultures or mixed cultures of $K$. veneficum on 3 separate dates. To differentiate between the 2 strains of $K$. veneficum within the mixed algal diets, NONTOX was stained with the vital green fluorescent dye, 5-chloromethylfluorescein diacetate (CMFDA, Molecular Probes) (Li et al. 1996). CMFDA dye was added to the NONTOX culture at a concentration of $0.5 \mu \mathrm{mol} \mathrm{l}^{-1}$ and incubated for $3 \mathrm{~h}$ in the dark. Prior to exposure to the CMFDA dye, an appropriate amount of the NONTOX culture was removed and held separate for use in a $100 \%$ NONTOX (no dye) treatment. Cultures of the K. veneficum strains were added to $500 \mathrm{ml}$ polycarbonate bottles in ratios of $75 \%$ TOX: $25 \%$ NONTOX, 50\% TOX:50\% NONTOX, and $25 \%$ TOX:75\% NONTOX $(75 \%$ TOX, $50 \%$ TOX and $25 \%$ TOX, respectively) and diluted with 20 ppt $0.22 \mu \mathrm{m}$ filtered seawater to a density of $5 \times 10^{6} \mathrm{cells}^{-1}$. Experiments were run in triplicate, with a total of 18 treatment bottles (food and copepods) and 15 control bottles (food only). Additionally, A. tonsa adults were exposed to a 'no food' treatment in which they were added to 3 bottles containing only $0.22 \mu \mathrm{m}$ filtered sea water. Experimental bottles were slowly inverted several times to ensure they were well mixed. Subsamples $(10 \mathrm{ml})$ were taken from each bottle to perform live cell counts using a Coulter Counter and $1 \mathrm{ml}$ from each was preserved in a $1.5 \mathrm{ml}$ cryovial with $1 \%$ gluteraldehyde for cell ratio analysis. A. tonsa adults were added to each of 18 treatment bottles containing one of the above-described diets and 3 'no food' treatment bottles. In total, $10 \mathrm{ml}$ of $0.22 \mu \mathrm{m}$ filtered sea water was added to each of the control bottles to maintain equivalent cell densities among treatment and control bottles. Experimental bottles were maintained at $22^{\circ} \mathrm{C}$ on a $12 \mathrm{~h}$ light-dark cycle with $54.5 \pm 12.0$ (SD) $\mu \mathrm{mol}$ quanta $\mathrm{m}^{-2} \mathrm{~s}^{-1}$ PAR for $22 \mathrm{~h}$.

Following incubation, experimental bottles were mixed through gentle inversion. Contents of treatment bottles were gently poured through a $150 \mu \mathrm{m}$ mesh sieve to gather the copepods. The filtrate from each bottle was collected in a clean container so that phytoplankton samples could be obtained. The bottle was then rinsed 3 times with filtered sea water to capture any remaining Acartia tonsa on the sieve. The residual water was collected in a second bottle and discarded. Retained copepods were gently rinsed into a small Petri dish. Total surviving and dead copepods were enumerated under a dissecting microscope. We removed $10 \mathrm{ml}$ subsamples from the initial filtrate of each bottle for live cell counts with a Coulter Counter as soon as the last sample had been collected. A $1 \mathrm{ml}$ subsample from each initial filtrate was also preserved in $1 \%$ gluteraldehyde for subsequent cell ratio analysis using fluorescent microscopy. Gluteraldehydepreserved subsamples were refrigerated and allowed to settle for a minimum of $12 \mathrm{~h}$. We pipetted $500 \mu \mathrm{l}$ from the bottom of each cryovial, dispensed it into Lab$\mathrm{Tek}^{\circledR} \mathrm{II}$ chamber slides and allowed it to settle for $1 \mathrm{~h}$. Cells were examined with epifluorescent microscopy at 40× using a Nikon TE300 Eclipse ${ }^{\mathrm{TM}}$ inverted microscope equipped with a long band pass fluorescein isothiocyanate (FITC) filter set $\left(\lambda_{\text {ex }}=460\right.$ to $500 \mathrm{~nm}$, $\lambda_{\mathrm{em}}=510 \mathrm{LP} \mathrm{nm}$, dichroic LP beamsplitter $505 \mathrm{~nm}$ ). Since long band pass filter sets allow emission of both green and orange wavelengths, both CMFDA-stained cells of NONTOX (fluorescing green) and unstained cells of TOX (autofluorescing orange) could be quantified. At least 100 cells were counted to establish the ratio of each strain in the experimental bottles.

Clearance and related ingestion rates were calculated using the equations of Frost (1972). Results are reported below in terms of both clearance rates, F, and ingestion rates, I, which are the product of clearance 
rates and the average cell concentration in the treatment bottle. Potential ingestion of one Karlodinium veneficum strain by the other was evaluated by comparing the actual algal growth constant, $k$, of mixed diet treatments with $k^{*}$, an estimate of algal growth calculated as the sum of the products of $k$ from each monoalgal diet and the ratio of each strain in the mixed diet. The actual algal growth constant, $k$, is defined as:

$$
k=\frac{\ln \left(C_{1} / C_{2}\right)}{T}
$$

where $C_{1}$ and $C_{2}$ are the cell concentrations (cells ml ${ }^{-1}$ ) in control bottles at the start and end of experimentation, respectively, and $T$ is the total time period (h) of the experiment (Frost 1972). The estimated algal growth, $k^{*}$ was calculated using:

$$
k^{*}=k_{\mathrm{TOX}}(\mathrm{r})+k_{\text {NONTOX }}(1-\mathrm{r})
$$

where $k_{\text {TOX }}$ and $k_{\text {NONTOX }}$ represent the actual algal growth constant of each monoalgal treatment and $\mathrm{r}$ is the ratio of that strain in the diet (i.e. $0.25,0.50,0.75$ ). To evaluate the possibility of heterotrophic grazing by one $K$. veneficum strain, a comparison of $k$ and $k^{*}$ was made. Survival, clearance and ingestion rates of Acartia tonsa were subjected to normality and equal variance testing. Data passing these tests were analyzed using 1-way factorial ANOVA and post hoc Tukey's HSD tests for multiple comparisons. Data failing normality and equal variance tests were subjected to log transformation prior to running 1-way ANOVA and post hoc Tukey's test for multiple comparisons. Cell ratio data were analyzed using 2-way ANOVA and the Holm-Sidak method for multiple comparisons. Student's $t$-test was used to compare C:N ratios of the $2 K$. veneficum strains and $k$ versus $k^{*}$. All analyses were conducted using SigmaStat v. 3.1.

\section{RESULTS}

\section{Biochemical analyses}

Elemental analysis of the 2 Karlodinium veneficum strains revealed significantly different $\mathrm{C}: \mathrm{N}$ ratios of $4.10 \pm 0.75$ (mean $\pm \mathrm{SD}$ ) for NONTOX and $5.58 \pm 0.22$ for TOX (Student's $t$-test, $t=-5.768, \mathrm{df}=16, \mathrm{p} \leq 0.001)$. $\mathrm{C}: \mathrm{N}$ ratios within NONTOX varied significantly between experiments ranging from $3.51 \pm 0.11$ for Experiment 1 to $5.09 \pm 0.02$ during Experiment 3 ( $F=479.69$, df $=2$, p $\leq$ 0.001). Ratios within TOX varied less, but still significantly, ranging from $5.36 \pm 0.54$ for Experiment 2 to $5.83 \pm 0.13$ during Experiment $1(F=24.20, \mathrm{df}=2, \mathrm{p}=0.001)$
(Table 1). NONTOX contained no karlotoxins and analysis provided consistent values of $0 \mathrm{ng}$ Karlotoxin $\mathrm{ml}^{-1}$ (Table 1). TOX contained the karlotoxin KmTx 2 at concentrations averaging $121.2 \pm 66.1 \mathrm{ng}$ KmTX 2 $\mathrm{ml}^{-1}$ (Table 1) or $1.15 \pm 0.70 \mathrm{pg} \mathrm{KmTx} 2$ cell $^{-1}$.

\section{Acartia tonsa survival and grazing rates}

Mean survivorship of Acartia tonsa ranged from $94.6 \pm 2.8$ to $97.6 \pm 2.8 \%$ within the individual grazing experiments and averaged $96.4 \pm 3.1 \%$ by combining the experiments (Fig. 1). No significant differences were found in copepod mortality among treatments in any of the experiments (Fig. 1A-C) $(F=0.769,1.88$, 2.128 , df $=6$, and $\mathrm{p}=0.607,0.160,0.115$ for Experiments 1,2 and 3 , respectively), or in combining the experiments (Fig. 1D) $(F=1.70, \mathrm{df}=6, \mathrm{p}=0.138)$. The lowest copepod survivorship, $90.8 \pm 1.4 \%$, was found in the no food treatment of Experiment 3 (Fig. 1C).

Acartia tonsa had reduced clearance and ingestion rates when its diet was dominated by TOX. Significant differences were found in clearance rates among treatments in each set of experiments (Fig. 2A-C) $(F=$ $5.827,14.157,3.23, \mathrm{df}=5$, and $\mathrm{p}=0.006,0.001,0.045$ for Experiments 1, 2 and 3, respectively) and ingestion rates among treatments in Experiments 1 and 2 (Fig. 3A,B) $(F=6.896,13.900, \mathrm{df}=5$, and $\mathrm{p}=0.003$, 0.001 for Experiments 1 and 2, respectively). Significant differences were also evident in clearance $(F=11.690, \mathrm{df}=5, \mathrm{p} \leq 0.001)$ and ingestion $(F=7.843$, $\mathrm{df}=5, \mathrm{p} \leq 0.001)$ rate activity of $A$. tonsa among treatments when combining the data from all 3 experiments (Figs. 2D \& 3D). Clearance rates were similar for the 2, $100 \%$ NONTOX (dye and no dye) treatments in Experiments 1 and 2, and in the combination of data from the 3 experiments (Fig. 2). A. tonsa ingestion rates of the $100 \%$ NONTOX (dye) and 100\% NONTOX (no dye) treatments were not significantly different in any of the 3 experiments or in the combined result of these experiments (Fig. 3).
Table 1. Karlodinium veneficum. Summary of the C:N ratios and toxin content of strains CCMP 2064 (TOX) and CSIC1 (NONTOX) on the 3 experimental dates. Data are means $( \pm \mathrm{SD}), \mathrm{n}=3$, for each experiment and strain

\begin{tabular}{|lcccc|}
\hline \multirow{2}{*}{ Experiment } & \multicolumn{2}{c}{ C:N } & \multicolumn{2}{c|}{ Karlotoxin $\left(\mathrm{ng} \mathrm{ml}^{-1}\right)$} \\
& NONTOX & TOX & NONTOX & TOX \\
\hline 1 & $3.51(0.11)$ & $5.83(0.13)$ & 0 & $177.3(23.9)$ \\
2 & $3.71(0.05)$ & $5.36(0.54)$ & 0 & $158.5(28.4)$ \\
3 & $5.09(0.02)$ & $5.55(0.03)$ & 0 & $52.6(7.7)$ \\
Overall mean & $4.10(0.75)$ & $5.58(0.22)$ & 0 & $121.2(66.1)$ \\
\hline
\end{tabular}



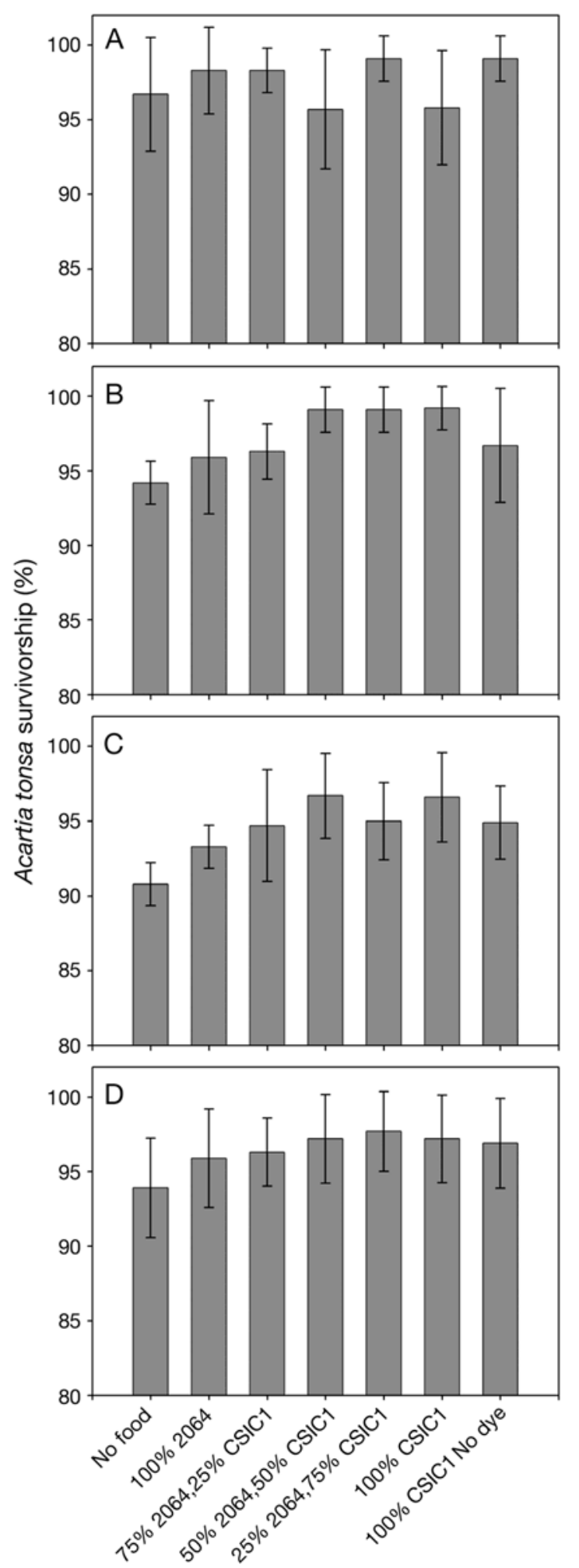

Fig. 1. Acartia tonsa. Mean survivorship (\%) following food removal experiments with monoalgal and mixed-algal diets of 'Karlodinium veneficum' strains CCMP 2064 (TOX) and CSIC1 (NONTOX) from (A) Experiment 1, (B) Experiment 2, (C) Experiment 3, and (D) Experiments 1-3 combined. Error bars indicate $1 \mathrm{SD}$
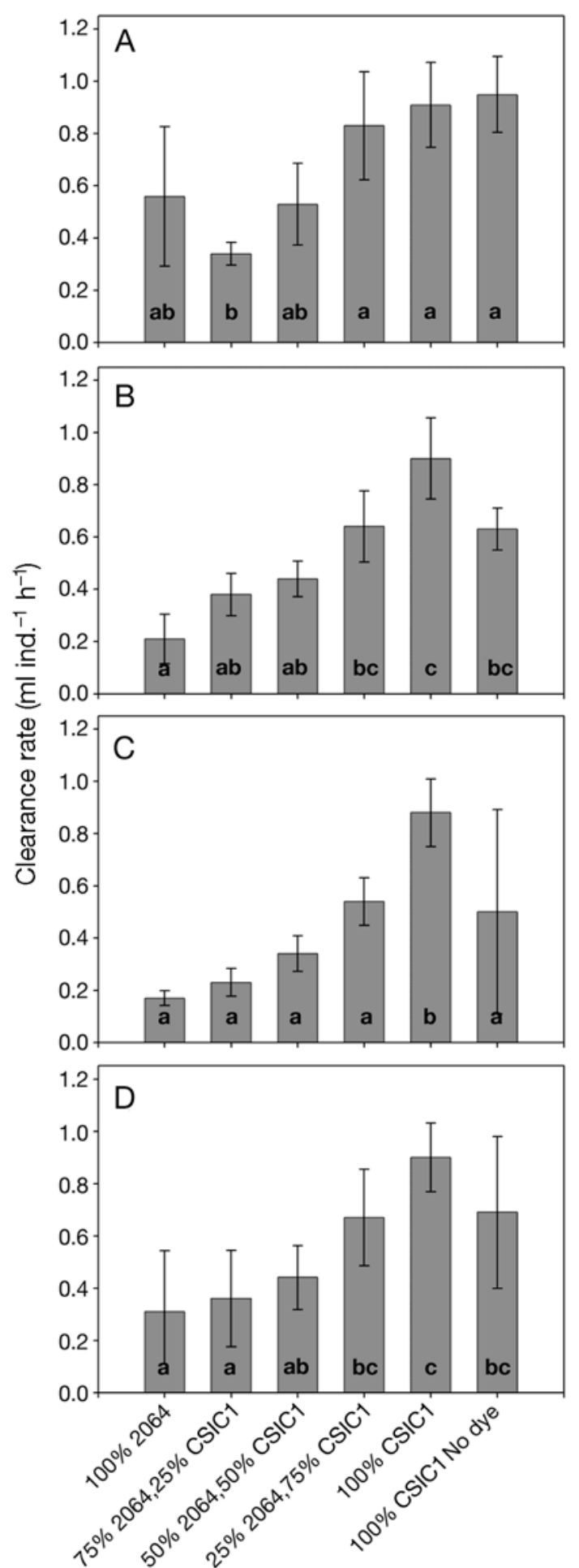

Fig. 2. Acartia tonsa. Mean clearance rates $\left(\mathrm{ml}\right.$ ind. $\left.{ }^{-1} \mathrm{~h}^{-1}\right)$ on monoalgal and mixed-algal diets of Karlodinium veneficum strains CCMP 2064 (TOX) and CSIC1 (NONTOX) from (A) Experiment 1, (B) Experiment 2, (C) Experiment 3, and (D) Experiments 1-3 combined. Error bars indicate $1 \mathrm{SD}$. Different letters $(a, b, c)$ on the bars indicate significant differences among treatments as revealed via 1-way ANOVA with post-hoc Tukey's HSD 

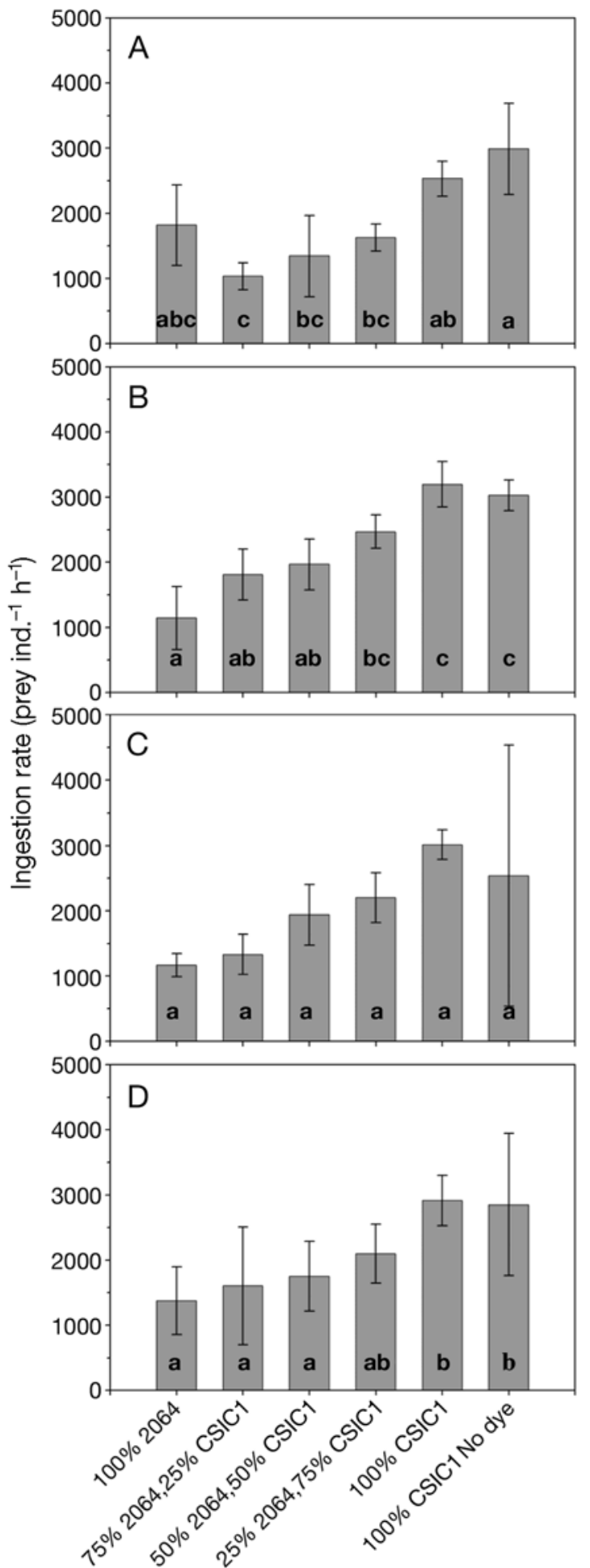

Fig. 3. Acartia tonsa. Mean ingestion rates (prey ind.$^{-1} \mathrm{~h}^{-1}$ ) on monoalgal and mixed-algal diets of Karlodinium veneficum strains CCMP 2064 (TOX) and CSIC1 (NONTOX) from (A) Experiment 1, (B) Experiment 2, (C) Experiment 3, and (D) Experiments 1-3 combined. Error bars indicate 1 SD. Different letters on the bars indicate significant differences among treatments as revealed via 1-way ANOVA with post-hoc Tukey's HSD
In Experiment 1, average clearance rates ranged from $0.34 \pm 0.04$ to $0.95 \pm 0.15 \mathrm{ml}$ ind..$^{-1} \mathrm{~h}^{-1}$ (Fig. 2A) and average ingestion rates from $1033.7 \pm 208.8$ to $2985.4 \pm 698.4$ prey ind. $^{-1} \mathrm{~h}^{-1}$ (Fig. 3A). Acartia tonsa clearance rates were highest in the $100 \%$ NONTOX (dye and no dye) and the 25\% TOX treatments and were significantly greater than in the $75 \%$ TOX treatment (Tukey's HSD test, $\mathrm{p}=0.018,0.012,0.046$, respectively). Ingestion rates were significantly greater in the $100 \%$ NONTOX (dye and no dye) treatments than in the $75 \%$ TOX treatment (Tukey's HSD test, $\mathrm{p}=0.025,0.004$, respectively), and A. tonsa ingestion rates on the $100 \%$ NONTOX (no dye) treatment were also significantly greater than on the $50 \%$ TOX and $25 \%$ TOX treatments (Fig. 3A) (Tukey's HSD test, $\mathrm{p}=0.014,0.045$, respectively). In Experiment 2, A. tonsa average clearance rates ranged from $0.21 \pm 0.09$ to $0.90 \pm 0.16 \mathrm{ml}$ ind. ${ }^{-1} \mathrm{~h}^{-1}$ and were highest in the $100 \%$ NONTOX (dye) treatment (Fig. 2B). Ingestion rates ranged from $1141.2 \pm 484.3$ to $3193.7 \pm 347.0$ prey ind. ${ }^{-1} \mathrm{~h}^{-1}$ and were highest in the $100 \%$ NONTOX (dye and no dye) treatments (Fig. 3B). Significantly higher clearance and ingestion rates were observed in the $100 \%$ NONTOX (dye and no dye) treatments and the $25 \%$ TOX than in the $100 \%$ TOX treatment (Tukey's HSD test, F: p = 0.001, 0.007, 0.006; I: p = $0.001,0.001,0.008)$. Additionally, A. tonsa had significantly greater clearance and ingestion rates in the $100 \%$ NONTOX (dye) treatment than in the $75 \%$ TOX and the $50 \%$ TOX treatments (Tukey's HSD test, F: $\mathrm{p}=$ $0.003,0.003 ; \mathrm{I}: \mathrm{p}=0.013,0.014)$. Similar results were found for Experiment 3. The highest clearance and ingestion rates were in the $100 \%$ NONTOX (dye) treatment and average rates ranged from $0.17 \pm 0.03$ to $0.88 \pm 0.13 \mathrm{ml}$ ind $^{-1} \mathrm{~h}^{-1}$ and $1166.1 \pm 178.5$ to $3015.3 \pm$ 227.0 prey ind..$^{-1} \mathrm{~h}^{-1}$, respectively (Figs. $2 \mathrm{C} \& 3 \mathrm{C}$ ). Significantly higher clearance rates were observed for the $100 \%$ NONTOX (dye) treatment than for the 100\% TOX treatments (Tukey's test, $\mathrm{p}<0.05$ ); however, no significant differences in ingestion rates were found among treatments due to the confounding effect of high variability in the $100 \%$ NONTOX (no dye) treatment. Removal of this treatment from the statistical analysis revealed significantly higher ingestion rates for the $100 \%$ NONTOX (dye) treatment than for the $100 \%$ TOX, $75 \%$ TOX and $50 \%$ TOX treatments (Tukey's HSD test, p < 0.001, 0.001, 0.013, respectively). Ingestion rates of the $25 \%$ TOX treatment were also significantly greater than in the $100 \%$ TOX and $75 \%$ TOX treatments (Tukey's HSD test, $\mathrm{p}=0.017$, 0.035 respectively).

Combining the results from all 3 experiments reinforced the observed trend of increased Acartia tonsa clearance and ingestion rates with a corresponding increase in the ratio of NONTOX in the given diet 
(Figs. 2D \& 3D). A. tonsa clearance rates in the $100 \%$ NONTOX (dye and no dye) and the $25 \%$ TOX treatments were significantly greater than in the $100 \%$ TOX (Tukey's HSD test, $\mathrm{p}=0.001,0.003,0.006)$ and $75 \%$ TOX (Tukey's HSD test, $\mathrm{p}=0.001,0.012,0.026$ ). Additionally, clearance rates were significantly greater in the $100 \%$ NONTOX (dye) treatment than in the $50 \%$ TOX treatment (Tukey's HSD test, $\mathrm{p}=0.001$ ). $A$. tonsa ingestion rates in the 100\% NONTOX (dye and no dye) treatments were significantly greater than in the $100 \%$ TOX (Tukey's HSD test, $\mathrm{p}=0.001,0.001$ ), $75 \%$ TOX (Tukey's HSD test, $\mathrm{p}=0.003,0.005$ ) and $50 \%$ TOX treatments (Tukey's HSD test, $\mathrm{p}=0.011$, $0.019)$.

In Experiment 1, there were no significant differences in the TOX:NONTOX ratio with the presence or absence of Acartia tonsa in any of the 3 mixed diet treatments (Table 2, Fig. 4A,B); however, significant differences were found in the TOX:NONTOX ratio at the start and end of the experiments (Table 2, Fig. 4A,B). No significant differences in the TOX:NONTOX ratios were found with either the presence or absence of $A$. tonsa in Experiment 2. Additionally, the TOX:NONTOX ratios were not significantly different at the start and end of the $75 \%$ TOX and 50\% TOX treatments (Table 2, Fig. 4C,D). In Experiment 3, there were no significant differences in the TOX:NONTOX ratio with either the presence or absence of $A$. tonsa or at the start and end of the experiments in any of the 3 mixed diet treatments (Table 2, Fig. 4E,F). In the combined results of Experiments 1, 2 and 3 , there were no significant differences in the TOX:NONTOX ratio with the presence or absence of A. tonsa in any of the 3 mixed diet treatments (Table 2,

Table 2. Karlodinium veneficum. Results of 2-way ANOVAs for the ratios of strains CCMP 2064 (TOX) and CSIC1 (NONTOX) with the presence or absence of Acartia tonsa predators (+/- A. tonsa) and Time (start/end) as factors

\begin{tabular}{|c|c|c|c|c|c|}
\hline \multirow[t]{2}{*}{ Experiment } & \multirow{2}{*}{$\begin{array}{l}\text { Treatment } \\
\text { (TOX level) }\end{array}$} & \multicolumn{2}{|c|}{$+/-$ A. tonsa } & \multicolumn{2}{|c|}{ Time } \\
\hline & & $F$ & $\mathrm{p}$ & $F$ & $\mathrm{p}$ \\
\hline \multirow[t]{3}{*}{1} & $75 \%$ & 1.47 & 0.260 & 112.38 & $<0.001$ \\
\hline & $50 \%$ & 0.61 & 0.458 & 15.86 & 0.004 \\
\hline & $25 \%$ & 0.80 & 0.396 & 10.16 & 0.013 \\
\hline \multirow[t]{3}{*}{2} & $75 \%$ & 1.02 & 0.342 & 2.74 & 0.137 \\
\hline & $50 \%$ & $<0.001$ & 0.987 & 4.34 & 0.071 \\
\hline & $25 \%$ & 0.03 & 0.863 & 18.35 & 0.003 \\
\hline \multirow[t]{3}{*}{3} & $75 \%$ & 0.49 & 0.503 & 0.25 & 0.633 \\
\hline & $50 \%$ & 0.008 & 0.932 & 3.94 & 0.082 \\
\hline & $25 \%$ & 0.13 & 0.733 & 0.85 & 0.384 \\
\hline \multirow[t]{3}{*}{ Combined } & $75 \%$ & 0.37 & 0.545 & 12.28 & $<0.001$ \\
\hline & $50 \%$ & 0.006 & 0.939 & 24.53 & $<0.001$ \\
\hline & $25 \%$ & 0.11 & 0.741 & 19.27 & $<0.001$ \\
\hline
\end{tabular}

Fig. 4G,H); however, significant differences were found in the TOX:NONTOX ratio at the start and end of the experiments (Table 2, Fig. 4G,H).

Algal growth, represented by positive $k$ values, was evident in all monoalgal treatments of $100 \%$ TOX (Fig. 5). Negative values of $k$ were measured for all monoalgal treatments of $100 \%$ NONTOX (dye). Similar trends were found when comparing $k$ and $k^{*}$ for all experiments and for the results of the combined experiments (Fig. 5). Significant differences between $k$ and $k^{*}$ were found only for the $50 \%$ TOX treatment in Experiment 2. The similarities in $k$ and $k^{*}$ in the remaining treatments indicated that no significant heterotrophic grazing occurred within the bottles during experimentation.

\section{DISCUSSION}

Exposure to diets dominated by TOX significantly reduced clearance and ingestion rates of the copepod Acartia tonsa. Clearance rates on the monoalgal diet of $100 \%$ NONTOX and the mixed algal diet of $25 \%$ TOX were significantly higher than other treatments. Significantly greater ingestion rates were also found for the $100 \%$ NONTOX treatment. These findings indicate that TOX suppressed total grazing efforts when comprising $\geq 50 \%$ of prey field and that karlotoxin may act as a chemical grazing deterrent to protect both the toxic strain and non-toxic, co-occurring species.

Phytoplankton species have evolved several antigrazing strategies to minimize population loss. These strategies can be categorized into 3 broad groups: morphological, behavioral, and chemical defense (Smetacek 2001). Morphological adaptations, such as large size, spines or chain and colony formation, represent the most conspicuous form of defense and act specifically to deter prey selection by grazers. On a behavioral level, motile phytoplankton may be capable of avoiding or escaping from predators, specifically smaller protozoan grazers (Buskey 1997, Tillmann \& Reckermann 2002). Other species, such as Karlodinium veneficum have evolved a chemical defense system against grazers. Chemical defense may involve complex interactions between phytoplankton prey and their grazers, such as excretion of chemical signals or the retention of toxic or unpalatable intracellular compounds. Predators may detect extracellular chemical signals produced by nearby phytoplankton, whereas intracellular compounds can only be de- 
tected through direct contact or consumption of the phytoplankton prey (Wolfe 2000).

Chemical defenses may deter grazing via 3 modes of action. First, the presence of an extracellular chemical or toxin may directly deter grazing (Poulet \& Marsot 1978, Teegarden 1999). Potential predators would detect the chemical in surrounding fluid and actively select against the nearby phytoplankton. A second strategy would involve 'trial and error' on the part of the grazer (Uye \& Takamatsu 1990). The consumption of prey with a toxic intracellular compound would be inimical to grazer health, forcing the grazer to reject similar particles. Finally, consumption of the phytoplankton prey could cause physiological incapacitation due to the presence of a toxic compound (Huntley et al. 1986, Ives 1987). Future grazing would be impossible for the paralyzed or dead predator.

The results of the current study suggest that trial and error, physiological incapacitation, or some combination of the two, act to suppress grazing in the predatorprey interactions between Acartia tonsa and toxic Karlodinium veneficum. It is unlikely that the first
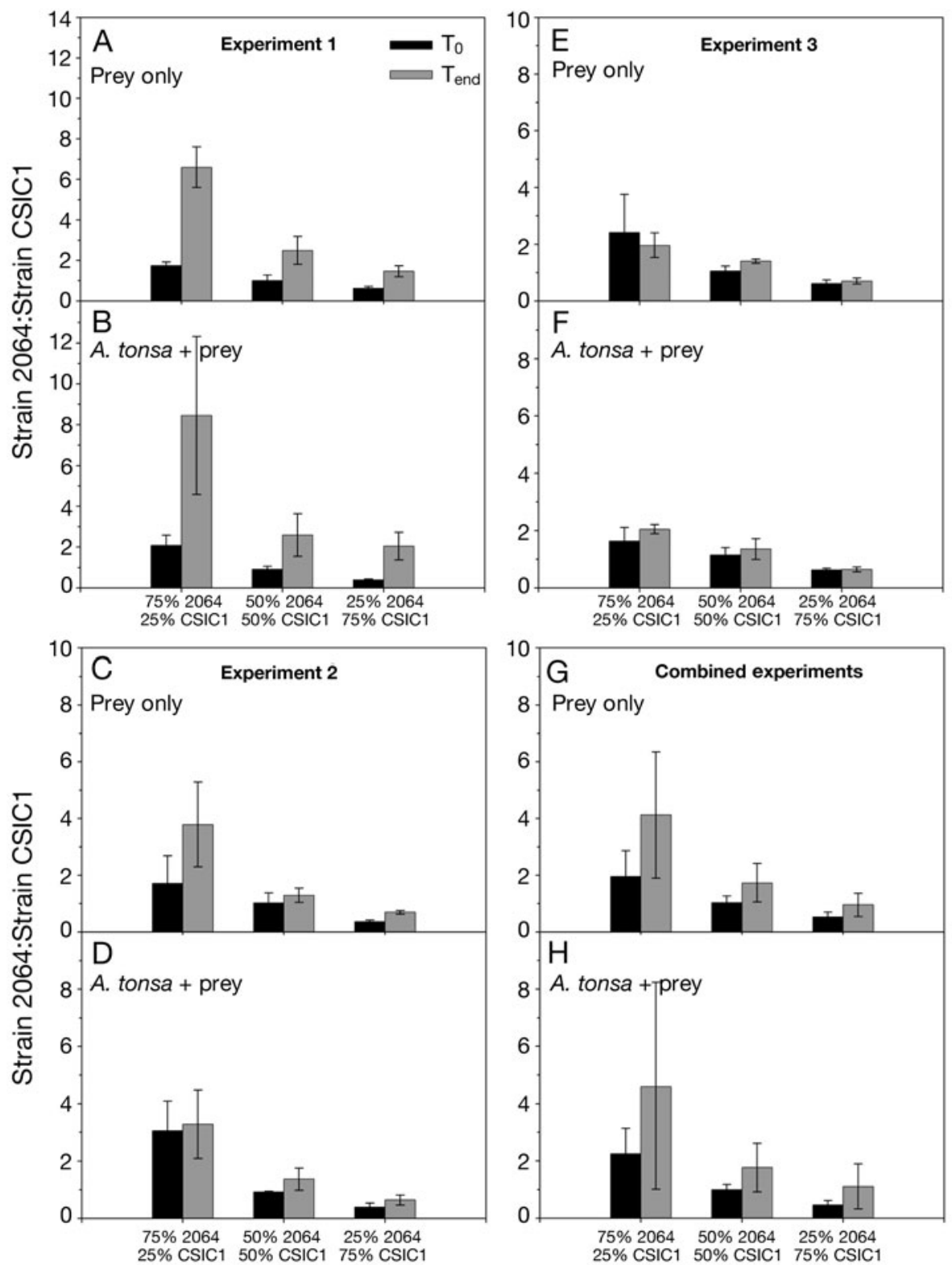

Fig. 4. Karlodinium veneficum. Ratio of strains CCMP 2064 (TOX) and CSIC1 (NONTOX) at the start ( $\left.\mathrm{T}_{0}\right)$ and end ( $\left.\mathrm{T}_{\text {end }}\right)$ of food removal experiments $(\mathrm{A}, \mathrm{C}, \mathrm{E})$ in control bottles and $(\mathrm{B}, \mathrm{D}, \mathrm{F})$ in the presence of Acartia tonsa grazers for Experiments 1, 2 and 3, and $(\mathrm{G})$ in control bottles and $(\mathrm{H})$ in the presence of $A$. tonsa grazers for the combined results of Experiments 1-3. Error bars indicate $1 \mathrm{SD}$ 
mode of action, release of an extracellular compound, was initially responsible for the suppression of grazing by A. tonsa. In non-grazed cultures, Adolf et al. (2007) found that free toxin levels were $<5 \%$ of total toxin content, suggesting that extracellular chemicals do not play a role in initially suppressing copepod grazing; however, direct contact with cells during grazing or release of toxins through 'sloppy feeding' may facilitate the release of karlotoxin or another anti-grazing metabolite into the surrounding fluid and act to further suppress grazing. In the current set of experiments, no significant mortality of $A$. tonsa was observed after $22 \mathrm{~h}$ incubation with $K$. veneficum. Additionally, no obvious differences were observed in copepod behavior among treatments at concentrations of ca. $5 \times$ $10^{3}$ cells $\mathrm{ml}^{-1}$; however, it is possible that sublethal effects of the toxin depressed some facet of copepod grazing behavior. Future studies are necessary to examine the behavioral effects of karlotoxin exposure on copepod feeding.

Trial and error grazing results in prey rejection of similar size/shape particles. Uye \& Takamatsu (1990) have suggested that trial and error grazing of toxic phytoplankton may be required so copepods can learn which species to avoid. Such particle rejection requires ingestion and is not the result of chemosensory recognition of the chemical feeding deterrent (Uye \& Takamatsu 1990). The results of the current study suggest that Acartia tonsa consumed enough of the toxic strain to learn that it should be avoided, but not enough for it to be lethal. In treatments with greater proportions of NONTOX, more consumption was necessary to deter grazing since the 2 strains could not be distinguished. Grazing rates were especially low when TOX constituted $50 \%$ or more of the total prey population, suggesting that the inimical costs of grazing were so high copepods chose not to eat anything.

Previous research indicates that copepods, including Acartia tonsa, are capable of detecting toxic dinoflagellate cells and actively avoiding them (Teegarden 1999). In mixed-culture grazing experiments, Teegarden (1999) found that A. tonsa, Centropages hamatus and Eurytemora herdmani utilized their chemosensory abilities to actively select for non-toxic clones of Alexandrium spp. over toxic clones. In the present set of experiments involving Karlodinium veneficum, no prey selection was evident, potentially due to the similar morphological characteristics and chemical exudates of TOX and NONTOX. The 2 strains are approximately the same size and shape and may potentially leak comparable metabolites (low molecular weight compounds, i.e. sugars, amino acids, polypeptides, and small lipids or proteins) via molecular diffusion advertising a similar chemical composition within their phycospheres (Bell \& Mitchell 1972, see

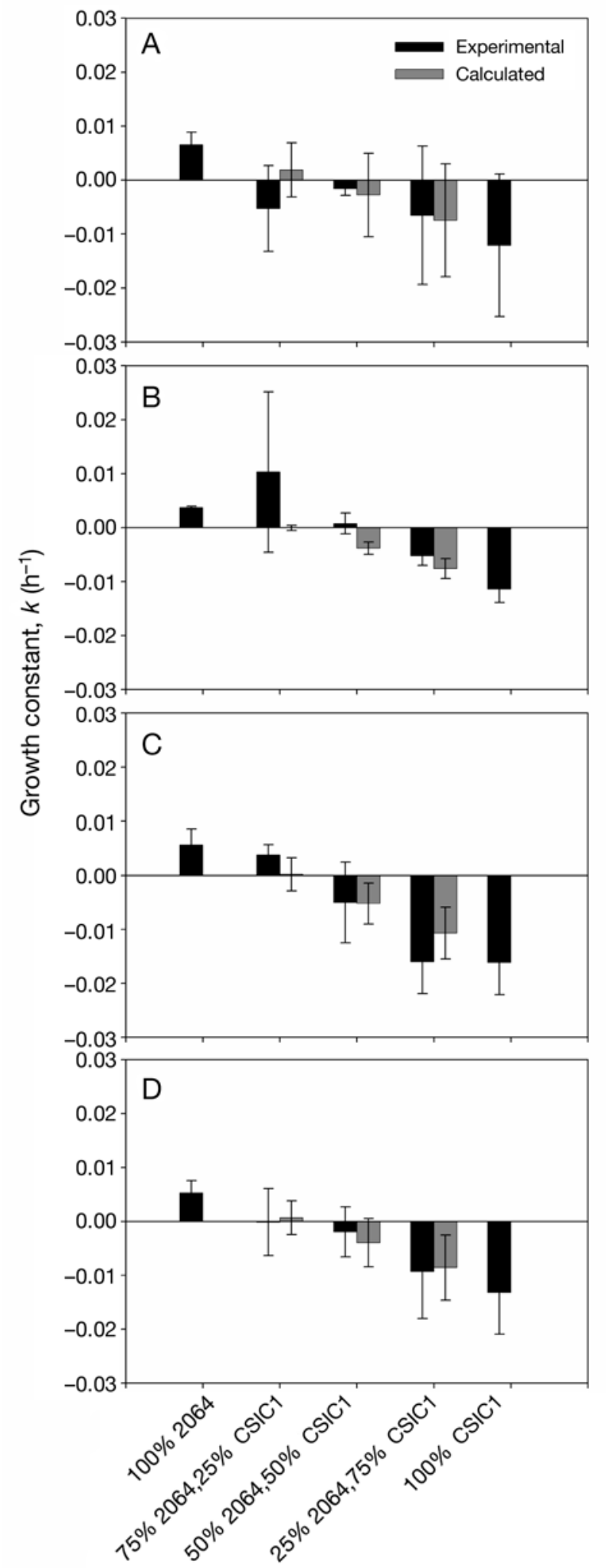

Fig. 5. Karlodinium veneficum. Actual and calculated algal growth constants $\left(\mathrm{h}^{-1}\right)$ of monoalgal and mixed-algal diets of strains CCMP 2064 (TOX) and CSIC1 (NONTOX) during (A) Experiment 1, (B) Experiment 2, (C) Experiment 3, and (D) the combined results of Experiments 1-3. Error bars indicate $1 \mathrm{SD}$ 
Wolfe 2000). Additionally, both strains were nitrogenreplete, indicating that they were nutritionally viable, although NONTOX had a significantly greater amount of nitrogen available (Table 1). The lack of prey selection indicates that $A$. tonsa was unable to distinguish the 2 strains via normal mechano- and chemoreceptive abilities.

Although copepods are capable of prey selection, in our experiments, grazing deterrence was non-selective. These findings reinforce the idea that karlotoxin confers a protection not only to the toxic Karlodinium veneficum strain CCMP 2064, but also to co-occurring species as well (Adolf et al. 2007, Adolf et al. in press). Evolutionary theory suggests that the benefit of the toxin must outweigh the potential costs of toxin production, including reductions in growth, reproduction and competitive ability. In the present experiments, we observed much greater growth rates for TOX than NONTOX, indicating that toxin production by TOX does not reduce its growth rate or competitive ability to acquire nutrients. Additionally, $K$. veneficum is capable of mixotrophic growth; therefore, co-occurring algae may be potential prey items. By shielding cooccurring species from zooplankton grazers, toxic $K$. veneficum strains may be protecting their own prey from larger, more efficient competitors and ensuring unrestricted access to a nutritious food source to enhance their growth (Adolf et al. 2007, Adolf et al. in press).

Grazing of Karlodinium veneficum was suppressed in treatments dominated by TOX; however, low amounts of grazing did occur, suggesting the possibility of small-scale toxin accumulation within copepod grazers. Long-term exposure to low levels of toxic $K$. veneficum may eventually be lethal to grazers due to either starvation or direct toxicity; however, toxin presence could select for individuals and grazer species that are less sensitive to the toxin. If the more sensitive grazer populations die out due to acute mortality or reduced reproduction, a more resilient composition of grazers could develop.

Although increased copepod mortality or physiological incapacitation during grazing assays were not observed in the present set of experiments, previous researchers have reported lethal effects of Karlodinium veneficum on copepod grazers. Delgado \& Alcaraz (1999) describe lethal effects of K. veneficum to the copepod grazer Acartia grani at concentrations $>3100$ cells ml ${ }^{-1}$ within hours of incubation. Low fecal pellet production during incubation suggested limited copepod grazing and suppressed feeding activity, prompting Delgado \& Alcaraz (1999) to propose an alternative mode of toxin activity: direct absorption of toxin via contact with the cell membrane or potential disruption of mechanical and chemical sensory sys- tems. However, since grazing rates were not directly measured, low levels of grazing could have released enough toxin to induce inimical effects on the copepods, or the activity of grazers could have disrupted cells releasing toxin into surrounding water. Similar incubations involving $K$. veneficum and copepod grazers A. grani and Euterpina acutifrons produced varying results. Exposure to $K$. veneficum at 2800 cells ml $^{-1}$ for $120 \mathrm{~h}$ had no effect on survival of the harpacticoid E. acutifrons, but A. grani survival was reduced to $70 \%$ (da Costa \& Fernandez 2002). Long-term exposure to $K$. veneficum at concentrations of $1500 \mu \mathrm{g} \mathrm{Cl}^{-1}$ had no effect on E. acutifrons survival, while $0 \%$ of $A$. grani survived (da Costa et al. 2005). Vaqué et al. (2006) examined grazing of 2 predators, the dinoflagellate Oxyrrhis marina and the copepod A. margalefi on $K$. veneficum at a range of cell concentrations (up to 2500 cells ml${ }^{-1}$ ) and at different N:P ratios. Although reduced grazing was observed for both $O$. marina and A. margalefi when consuming $K$. veneficum, after $24 \mathrm{~h}$ exposure, no lethal or paralyzing effects were observed (Vaqué et al. 2006).

The varying effects of karlotoxins on copepod grazers are most likely the result of differential toxin levels in Karlodinium veneficum strains used in the experiments. Delgado \& Alcaraz (1999) used wild, noncultured $K$. veneficum, which had the most lethal effect on copepod grazers, suggesting that toxin levels of this wild strain were much higher than in cultured $K$. veneficum used in grazing experiments of other investigators (da Costa \& Fernandez 2002, da Costa et al. 2005, Vaqué et al. 2006, present study). Interestingly, the grazing experiments of Vaqué et al. (2006) involved $K$. veneficum CSIC1 as a toxic prey item, whereas in the current study strain CSIC1 was used as a non-toxic control, since toxin analysis revealed $0 \mathrm{ng}$

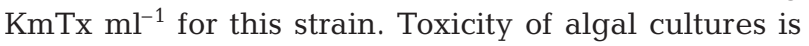
known to vary with time and culture conditions (Maranda et al. 1985, Bates et al. 1993). So, although toxin levels were not quantified in the Vaqué et al. (2006) study, it is likely that their cultures of CSIC1 were toxic at the time of experimentation.

Karlotoxins are membrane-disrupting compounds that interact strongly with certain membrane sterols, such as cholesterols (Deeds \& Place 2006). These sterols form stable complexes with karlotoxins, thereby increasing the ionic permeability of the affected membranes. Organisms with a predominance of desmethyl sterols, such as cholesterols, are therefore more vulnerable to the effects of karlotoxins. The heterotrophic dinoflagellate Oxyrrhis marina, a potential grazer of Karlodinium veneficum, contains cholesterol as its dominant membrane sterol (Deeds \& Place 2006, Adolf et al. 2007). Exposure to high levels $\left(\geq 300 \mathrm{ng} \mathrm{ml}^{-1}\right.$ ) of purified karlotoxin caused lysis of 
O. marina (Deeds \& Place 2006, Adolf et al. 2007) and, at lower concentrations more consistent with levels found in nature $\left(100 \mathrm{ng} \mathrm{ml}^{-1}\right)$, grazing of $O$. marina was inhibited (Adolf et al. 2007).

Generally, cholesterol is the dominant sterol found in copepods and has been reported to account for 89 to $99 \%$ of sterols in field-caught and lab-raised Acartia tonsa (Goad 1981, Ederington et al. 1995). In the present study, the reduction in grazing intensity observed in $A$. tonsa when exposed to increasing densities of TOX is consistent with the hypothesis that the effects of karlotoxins are dependent on the abundance of desmethyl sterols, in this case cholesterols, within the target organism. Additionally, although copepods are cholesterol-rich organisms, they are believed to be incapable of de novo synthesis of membrane sterols, relying instead on dietary sources for sterol acquisition (Goad 1981, Ederington et al. 1995, Crockett \& Hassett 2005). Karlodinium veneficum does not contain cholesterol, but has a sterol profile dominated by gymnodinosterol (Deeds \& Place 2006). Therefore, it raises the question of whether copepods, specifically A. tonsa, could survive on a diet dominated by $K$. veneficum for long periods of time. Copepod egg production can be either enhanced or limited by dietary cholesterol levels (Crockett \& Hassett 2005). Copepods exposed to diets dominated by $K$. veneficum may not only be affected by the karlotoxins, but also may suffer a reduction in egg production due to the limited availability of cholesterols.

\section{CONCLUSIONS}

A complex interaction of physical and biological forces contributes to the formation of HABs, including blooms of Karlodinium veneficum (Hall et al. 2008). The current study demonstrates the effect of karlotoxins on the suppression of copepod grazing. The antigrazing properties of $K$. veneficum, imparted by karlotoxins, may also contribute to both the success and persistence of a HAB. Grazing deterrence appears to be non-selective, suggesting that during a natural bloom zooplankton grazers would avoid not only toxic strains of $K$. veneficum but also non-toxic co-occurring algae. By protecting non-toxic counterparts from larger competitors, toxic $K$. veneficum can capitalize on their mixotrophic capabilities to facilitate rapid growth and contribute to the persistence of a bloom event. We would further expect bloom formation to favor the success of the more toxic species or strain, since grazing suppression should be greater in the presence of higher toxin concentrations due either to greater abundance of a toxic species, as demonstrated here, or greater toxin content per individual cell.
Acknowledgements. We thank J. E. Adolf of COMB UMBI for toxin analysis of Karlodinium veneficum strains. M. W. Vandersea offered advice and guidance with our CMFDA staining protocol. We are grateful to R. W. Litaker and S. Kibler for critical review of this manuscript. Funding for R.J.W. was provided through a NRC RAP postdoctoral research associateship funded by the CCFHR, NOS, NOAA. This paper is partially a result of research funded by the National Oceanic and Atmospheric Administration Coastal Ocean Program under award \#NA04NOS4780276 to University of Maryland Biotechnology Institute. This is contribution \# 08-183 from the Center of Marine Biotechnology and contribution \#267 from the ECOHAB program.

\section{LITERATURE CITED}

Adolf JE, Krupatkina D, Bachvaroff T, Place AR (2007) Karlotoxin mediates grazing by Oxyrrhis marina on strains of Karlodinium veneficum. Harmful Algae 6:400-412

Adolf JE, Bachvaroff T, Place AR (in press) Manger à trois: Toxic and non-toxic Karlodinium veneficum strains with a predator, Oxyrrhis marina and a prey, Storeatula major. In: Moestrup $\varnothing$ et al. (eds) Proceedings of the 12th International Conference on Harmful Algae, Copenhagen, Denmark, International Society for Harmful Algae and Intergovernmental Oceanographic Commission of UNESCO, Copenhagen

Bachvaroff TR, Adolf JE, Squier AH, Harvey HR, Place AR (2008) Characterization and quantification of karlotoxins by liquid chromatography-mass spectrometry. Harmful Algae (in press) doi:10.1016/j.hal.2007.10.003

Bates SS, Worms J, Smith JC (1993) Effects of ammonium and nitrate on growth and domoic acid production by Nitzschia pungens in batch culture. Can J Fish Aquat Sci 50:1248-1254

Bell W, Mitchell R (1972) Chemotactic and growth responses of marine bacteria to algal extracellular products. Biol Bull 143:265-277

> Bergholtz T, Daugbjerg N, Moestrup $\varnothing$, Fernandez-Tejedor M (2006) On the identity of Karlodinium veneficum and description of Karlodinium armiger sp. nov. (Dinophyceae), based on light and electron microscopy, nuclear-encoded LSU RDNA, and pigment composition. J Phycol 42:170-193

Buskey EJ (1997) Behavioral components of feeding selectivity of the heterotrophic dinoflagellate Protoperidinium pellucidum. Mar Ecol Prog Ser 153:77-89

Crockett EL, Hassett RP (2005) A cholesterol-enriched diet enhances egg production and egg viability without altering cholesterol content of biological membranes in the copepod Acartia hudsonica. Physiol Biochem Zool 78: 424-433

da Costa RM, Fernandez F (2002) Feeding and survival rates of the copepods Euterpina acutifrons Dana and Acartia grani Sars on the dinoflagellates Alexandrium minutum Balech and Gyrodinium corsicum Paulmier and the Chryptophyta Rhodomonas baltica Karsten. J Exp Mar Biol Ecol 273:131-142

da Costa RM, Franco J, Cacho E, Fernández F (2005) Toxin content and toxic effects of the dinoflagellate Gyrodinium corsicum (Paulmier) on the ingestion and survival rates of the copepods Acartia grani and Euterpina acutifrons. J Exp Mar Biol Ecol 322:177-183

Deeds JR, Place AR (2006) Sterol-specific membrane interactions with the toxins from Karlodinium micrum (Dinophyceae) - a strategy for self-protection? Afr J Mar Sci 28: 421-427 
Deeds JR, Terlizzi DE, Adolf JE, Stoecker DK, Place AR (2002) Toxic activity from cultures of Karlodinium micrum (=Gyrodinium galatheanum) (Dinophyceae) - a dinoflagellate associated with fish mortalities in an estuarine aquaculture facility. Harmful Algae 1:169-189

Deeds JR, Kibler SR, Tester PA, Place AR (2004) Geographic strain variation in toxin production in Karlodinium micrum (Dinophyceae) from Southeastern estuaries of the United States. In: Steidinger KA, Landsberg JH, Tomas CR, Vargo GA (eds) Harmful Algae 2002. Florida Fish and Wildlife Conservation Commission, Florida Institute of Oceanography, and Intergovernmental Oceanographic Commission of UNESCO, St. Petersburg, p 145-147

> Deeds JR, Reimschuessel R, Place AR (2006) Histopathological effects in fish exposed to the toxins from Karlodinium micrum. J Aquat Anim Health 18:136-148

Delgado M, Alcaraz M (1999) Interactions between red tide microalgae and herbivorous zooplankton: the noxious effects of Gyrodinium corsicum (Dinophyceae) on Acartia grani (Copepoda: Calanoida). J Plankton Res 21:2361-2371

Ederington MC, Mcmanus GB, Harvey HR (1995) Trophic transfer of fatty-acids, sterols, and a triterpenoid alcohol between bacteria, a ciliate, and the copepod Acartia tonsa. Limnol Oceanogr 40:860-867

Fensin EE (2004) Occurrence and ecology of the dinoflagellate Karlodinium micrum in estuaries of North Carolina, USA. In: Steidinger KA, Landsberg JH, Tomas CR, Vargo GA (eds) Harmful Algae 2002. Florida Fish and Wildlife Conservation Commission, Florida Institute of Oceanography, and Intergovernmental Oceanographic Commission of UNESCO, St. Petersburg, p 62-64

Frost BW (1972) Effects of size and concentration of food particles on the feeding behavior of the marine planktonic copepod Calanus pacificus. Limnol Oceanogr 17:805-815

Garcés E, Fernandez M, Penna A, Van Lenning K, Gutierrez A, Camp J, Zapata M (2006) Characterization of NW Mediterranean Karlodinium spp. (Dinophyceae) strains using morphological, molecular, chemical, and physiological methodologies. J Phycol 42:1096-1112

Goad LJ (1981) Sterol biosynthesis and metabolism in marine invertebrates. Pure Appl Chem 53:837-852

Granéli E, Olsson P, Carlsson P, Granéli W, Nylander C (1993) Weak 'top-down' control of dinoflagellate growth in the coastal Skagerrak. J Plankton Res 15:213-237

Hall NS, Litaker RW, Fensin E, Adolf JE, Bowers HA, Place AR, Paerl HW (2008) Environmental factors contributing to the development and demise of a toxic dinoflagellate (Karlodinium veneficum) bloom in a shallow, eutrophic, lagoonal estuary. Estuaries Coasts 31:402-418

Huntley M, Sykes P, Rohan S, Marin V (1986) Chemicallymediated rejection of dinoflagellate prey by the copepods Calanus pacificus and Paracalanus parvus: mechanism, occurrence and significance. Mar Ecol Prog Ser 28: $105-120$

Editorial responsibility: Peter Verity,

Savannah, Georgia, USA
Ives JD (1987) Possible mechanisms underlying copepod grazing responses to levels of toxicity in red tide dinoflagellates. J Exp Mar Biol Ecol 112:131-145

Keller MD, Selvin RC, Claus W, Guillard RRL (1987) Media for the culture of oceanic ultraphytoplankton. J Phycol 23:633-638

Kempton JW, Lewitus AJ, Deeds JR, Law JM, Place AR (2002) Toxicity of Karlodinium micrum (Dinophyceae) associated with a fish kill in a South Carolina brackish retention pond. Harmful Algae 1:233-241

> Li A, Stoecker DK, Coats DW, Adam EJ (1996) Ingestion of fluorescently labeled and phycoerythrin-containing prey by mixotrophic dinoflagellates. Aquat Microb Ecol 10:139-147

Liu H, Buskey EJ (2000) The exopolymer secretions (EPS) layer surrouding Aureoumbra lagunensis cells affects growth, grazing, and behavior of protozoa. Limnol Oceanogr 45:1187-1191

Maranda L, Anderson DM, Shimizu Y (1985) Comparison of toxicity between populations of Gonyaulax tamarensis of eastern North American waters. Estuar Coast Shelf Sci 21:401-410

Nielsen TG (1991) Contribution of zooplankton grazing to the decline of a Ceratium bloom. Limnol Oceanogr 36: 1091-1106

Poulet SA, Marsot P (1978) Chemosensory grazing by marine calanoid copepods (Arthropoda: Crustacea). Science 200: 1403-1405

Smetacek V (2001) A watery arms race. Nature 411:745

Stoecker DK, Sanders NK (1985) Differential grazing by Acartia tonsa on a dinoflagellate and a tintinnid. J Plankton Res 7:85-100

> Teegarden GJ (1999) Copepod grazing selection and particle discrimination on the basis of PSP toxin content. Mar Ecol Prog Ser 181:163-176

- Teegarden GJ, Cembella AD (1996) Grazing of toxic dinoflagellates, Alexandrium spp, by adult copepods of coastal Maine: implications for the fate of paralytic shellfish toxins in marine food webs. J Exp Mar Biol Ecol 196:145-176

> Tillmann U, Reckermann M (2002) Dinoflagellate grazing on the raphidophyte Fibrocapsa japonica. Aquat Microb Ecol 26:247-257

> Uye S, Takamatsu K (1990) Feeding interactions between planktonic copepods and red-tide flagellates from Japanese coastal waters. Mar Ecol Prog Ser 59:97-107

Vaqué D, Felipe J, Sala MM, Calbet A, Estrada M, Alcaraz M (2006) Effects of the toxic dinoflagellate Karlodinium sp. (cultured at different N/P rations) on micro and mesozooplankton. Sci Mar 70:59-65

- Watras CJ, Garcon VC, Olson RJ, Chisholm SW, Anderson DM (1985) The effect of zooplankton grazing on estuarine blooms of the toxic dinoflagellate Gonyaulax tamarensis. J Plankton Res 7:891-908

> Wolfe GV (2000) The chemical defense ecology of marine unicellular plankton: constraints, mechanisms, and impacts. Biol Bull 198:225-244

Submitted: January 30, 2008; Accepted: April 9, 2008

Proofs received from author(s): August 8, 2008 